\title{
ASPECTOS ERGONÔMICO DA MODA PARA PESSOAS COM HIPERIDROSE
}

\author{
Laís Regina Faganello (1); \\ Luís Carlos Paschoarelli (2) \\ Fausto Orsi Medola (3)
}

(1) UNESP, Mestrado em Design

e-mail: laisfaganello@hotmail.com

(2) UFSCAR, Doutor em Engenharia de Produção

e-mail: paschoarelli@faac.unesp.br

(3) USP, Doutor em Bioengenharia

e-mail: fausto.medola@faac.unesp.br

\section{RESUMO}

Atualmente, as pessoas procuram um vestuário que proporcione conforto. Entretanto, em relação a fatores ergonômicos tais como a transpiração excessiva, o vestuário carece de apropriações aos usuários. Neste sentido, foi realizado um estudo por meio de um questionário online para avaliar a percepção de pessoas, homens e mulheres, com e sem hiperidrose, que realizaram ou não a cirurgia de intervenção para esta disfunção, a qual causa efeitos compensatórios, como uma sudorese em outras regiões do corpo. Nesta perspectiva, foi pertinente ao optar por um vestuário com melhores aspectos ergonômicos para a transpiração excessiva.

Palavras chave: ergonômico, vestuário, hiperidrose.

\section{ABSTRACT}

Nowadays, people look for a garment that provides comfort. However, for ergonomic factors such as excessive sweating, clothing needs to change for the benefit of users. In this regard, a study was done of an online questionnaire to evaluate the perception of people, men and women, with and without dysfunction, they had done or not surgery hyperidrosis, which causes compensatory effects, like a sweating in other parts of the body. In this perspective, the result was relevant to choose a garment with better ergonomic aspects.

Key words: ergonomic, garment, sweating. 


\section{INTRODUÇÃO}

A ergonomia se preocupa com a interação do homem com o mundo a sua volta. Entre os muitos objetos que o homem interage no seu dia a dia está o vestuário, que é do interesse do design e que são produtos gerados por meio de projetos que utilizam os requisitos gerados pela ergonomia.

Para o design de moda, além da antropometria e biomecânica, também é bastante relevante os aspectos subjetivos que a ergonomia agrega ao projeto, tais como fatores relacionados a percepção dos sujeitos com relação ao vestuário. Ainda sobre a percepção, que está relacionada aos sentidos, destaca-se o conforto que trata da ausência de constrangimentos físicos, psíquicos e emocionais relacionados ao uso de um produto.

Neste sentido, destacam-se questões relacionadas ao uso do vestuário e que precisam ser melhoradas. Principalmente no que tange casos específicos, como por exemplo, a hiperidrose, disfunção das glândulas sudoríparas

Este trabalho tem como propósito conhecer a percepção declarada de conforto de pessoas com e sem hiperidrose sobre o vestuário.

\section{REVISÃO BIBLIOGRÁFICA}

\subsection{DESIGN ERGONÔMICO DE MODA}

O design de moda envolve vários fatores a serem analisados, sejam estas "considerações acerca das variações antropométricas, morfológicas e biomecânicas do sujeito. Esses fatores possibilitam que o produto de vestuário seja desenvolvido de maneira a colaborar com um resultado satisfatório, seguro e confortável aos usuários" (NEVES E PASCHOARELLI, pág. 57, 2015).

Um dos motivos do surgimento do vestuário é a proteção, no estudo da indumentária os povos antigos usavam couros e peles de animais como proteção. De acordo com lida (2005), a usabilidade relaciona-se ao conforto e também com a eficiência dos produtos.

Não é apenas os aspectos visuais que devem ser avaliados ao projetar um produto de design, mas também aspectos relacionados aos demais sentidos. No design de moda, isso pode referir-se ao odor que determinadas roupas deixam quando não possuem as propriedades técnicas desejáveis de manutenção, fazendo com que o odor fique nítido em menor tempo, prejudicando a usabilidade sensorial. Além disso, estes fatores podem influenciar no ciclo devida de um produto, uma vez que estes odores e umidade causada pela sudorese na roupa podem levar a necessidade de maior frequência de lavagem. Esta é uma questão de projeto, uma vez que pode estar relacionada a escolha do tecido, um exemplo: por ter uma porcentagem maior de poliéster do que de algodão na composição. Isto causa desconforto. (BROEGA E SILVA, 2010).

Isto ocorre porque o tipo de material confeccionado também influencia no processo de trocas térmicas. Por isto, estuda-se o conforto termo fisiológico, onde a 
roupa precisa proteger das condições adversas que influenciam no processo mecânico do organismo de manter o equilíbrio corporal.

\subsection{CONFORTO TÉRMICO}

O conforto térmico, de acordo com Alencar (2014), depende de várias variáveis: seja elas fatores externos e climáticos tais como a umidade relativa do ar, velocidade do vento, a temperatura do ar e sensação térmica. $E$ também de fatores internos, tais como produção de calor do próprio metabolismo em si e o tipo de vestuário que o indivíduo utiliza. Por exemplo, em algumas situações da vida, as mulheres sentem mais frio que os homens. E também o contrário.

Outros fatores relacionados a doenças crônicas, também podem interferir tais como diabete, obesidade, tireóide, entre outras (HASIMOTO, 2012). Segundo Grambell (2002), quando a temperatura do meio externo excede a do corpo, por exemplo, acima dos $36^{\circ} \mathrm{C}$, a sudorese leva a uma perda compensatória de calor, por meio da evaporação. E, de acordo com Cohen e Wood (2002), quando a perda de calor excede mais de $60 \%$, ou seja, a maioria do que o corpo permite, a perspiração não evapora tão facilmente, ocasionando na pessoa uma reação desagradável, com queda da pressão sanguínea, podendo levar ao desmaio ou casos mais sérios.

O conforto térmico é obtido por trocas térmicas, cujas trocas dependem de fatores adversos, externos e internos, tais como: velocidade relativa do ar, temperatura do ar, umidade relativa e sensação térmica. Ou até mesmo de fatores pessoais como o metabolismo da própria pessoa e suas disfunções.

\subsection{HIPERIDROSE}

Trata-se de uma disfunção do organismo, causada por uma excessiva atividade das glândulas sudoríparas, devido a esta hiperativade, por isto o nome "hiper" em junção a hidrose, o qual se refere ao processo normal do organismo de homeostase, de troca de calor pela transpiração, o qual apresenta de modo exagerado em determinados grupos de pessoas. As glândulas sudoríparas responsáveis pelo suor se subdividem em dois tipos, as écrinas e apócrinas, sendo que as primeiras se distribuem pelo corpo todo. Já as apócrinas são mais volumosas e existem em apenas algumas zonas do corpo e de modo menos abundante (CORSO, 2008)

As regiões nas quais as glândulas mais se concentram são as mãos, plantas dos pés, crânio e região dorsal (MALAGI, 2012). A quantidade de suor produzida de acordo com Fraga (2009), pode aumentar em ambientes com climas elevados e pela prática de exercícios físicos. O normal da temperatura corpórea necessária para manter o equilíbrio, denominado homeostase, é cerca de $37^{\circ} \mathrm{C}$. Quando esta temperatura sobe, o hipotálamo, que é responsável por este equilíbrio térmico, ocasiona hiperatividade nas glândulas sudoríparas, de modo que estas podem chegar a produzir até 1, 5 litros por hora em uma pessoa normal. E, isto pode mudar se for uma pessoa que apresenta o quadro da hiperidrose. Outros fatores causam a secreção, tais como stress e nervosismo, e o fato é que quando o mesmo é causado apenas por fatores psicológicos só ocorrem nas mãos e nos pés. 
Há outros meios do corpo realizar mecanismo de equilíbrio como vasoconstrição, vasodilatação e tremor. Deste modo, o corpo pode perder calor tanto pela eliminação do suor como pela respiração, radiação e convicção de acordo com variáveis como temperatura ambiente, entre outros fatores, tais como umidade relativa do ar, por exemplo. (GUYTON, 1996).

O grupo de pessoas que apresentam a disfunção é um número expressivo, representando cerca de 2,8 a $4,6 \%$ da população mundial. Isso sem considerar, as pessoas que nem sabem que possuem tal problema. STRUTTON ET. AL. (2004) e TU YR ET. AL. (2007). Não depende de fatores externos para que se desencadeie o problema. Entretanto, fatores externos tornam influenciadores agravantes. Deste modo, independente de temperatura, situação climática ou condições o indivíduo transpira excessivamente em apenas algumas regiões.

Esta, por sua vez, pode se manifestar por todo o corpo de modo espalhado, ou fixar-se em uma ou mais regiões simultaneamente. Estas regiões são a palmar, plantar, axilar, infra mamária, inguinal ou craniofacial. A hiperidrose também pode se classificar como hiperidrose primária, a qual se caracteriza por ser local e não ter causa específica. Já a segunda, está associada a algum quadro clínico, como por exemplo doenças neoplásticas, endócrinas, como, metabólicas ou alcoolismo. Outro exemplo destas patologias que manifestam uma sudorese excessiva é a diabete ou obesidade.

Este distúrbio é simples de ser identificado, visto que as glândulas écrinas aumentam seu tamanho em até oito vezes. Os diagnósticos em geral possuem uma precisão de que esta hiperatividade das glândulas ocorra pelo menos uma vez por semana e antes dos 25 anos. E, por último ser considerado pela pessoa que a mesma atrapalhe totalmente a qualidade de vida. No caso de pacientes diagnosticados com hiperidrose palmar, por exemplo, apresentam a palma das mãos frias, úmidas e com coloração rubra. (YASBEK, 2009).

Conforme o Portal PSD (2015), Sociedade Brasileira de Dermatologia, há dois tipos de diagnósticos, sendo que na primária as pessoas não transpiram quando dormem ou em repouso, e só em regiões específicas como as já citadas anteriormente. Além do fato de que é genético, ou seja, mais pessoas da família tendem a apresentar o distúrbio. São realizados dois testes, um deles é o do amidoiodo, consiste em uma aplicação de uma solução de iodo para a área suada e, após a secagem, o amigo é aspergido sobre a região. A região fica azul escura devido a reação do amido com o suor. Já, o outro método é o papel de teste. Um papel especial é colocado sob a área para que se absorva o suor, após este procedimento, é pesado, é comprovado a transpiração excessiva se tiver maior densidade.

Há opções de tratamentos por meio tópico e cirúrgico. O tratamento tópico trata-se de toxina botulínica purificada que pode ser injetada na axila, nas mãos ou pés de modo a bloquear temporariamente os nervos. Por meio de antitranspirantes, a pessoa utiliza medicamentos, que nada mais é que drogas anticolinérgicas que impedem a estimulação das glândulas sudoríparas. Porém, pouco recomendado pelos médicos e estudiosos da área da saúde devido a efeitos colaterais. 
Outro método é a lontoforese que consiste no uso da eletricidade de modo a desligar temporariamente a glândula de suor, este tipo é mais usado em mãos e pés. É um tratamento com uma escala de desconforto de dor, pois o paciente sente um leve formigamento devido ao pequeno choque das correntes elétricas a qual o pé é colocado na água. Além de ser considerado doloroso, por provocar bolhas, é um tratamento considerado longo e demorado pelo paciente e ainda assim, não resolve totalmente o problema.

Apesar, de que nenhum dos métodos é uma garantia de que se resolva totalmente a disfunção. O tratamento cirúrgico, por exemplo, na maioria das vezes apresentará efeitos colaterais. A opção cirúrgica é denominada simpatectomia. E pode ser feito tanto pela simpatectomia torácica como a lombar. (GONÇALVES E SANTOS, 2010).

Conforme Montessi et. al. (2007), a primeira cirurgia foi realizada no início do século passado, a via utilizada era a cervical anterior, onde o gânglio estrelado era prejudicado, resultando em resultados não satisfatórios. Com a evolução da medicina, e consequentemente dos processos cirúrgicos, surgindo o método vídeo cirúrgico. A cirurgia é minimamente invasiva. A cirurgia se baseia em fechar o gânglio que transmite sinais ao corpo para que se transpire excessivamente. Esta é mais utilizada para a região palmar e quando nenhum dos tratamentos funcionaram. Há casos que esta cirurgia não é recomendada, como em pacientes que possuem a hiperidrose axilar, pois para esta última são necessárias outras seções dos gânglios. (COSTA, 2014).

\subsection{CONSIDERAÇÕES ERGONÔMICAS E A HIPERIDROSE COMPENSATÓRIA}

A hiperidrose possui o nome compensatória porque de fato o organismo compensa o suor para outras áreas do corpo como uma resposta ao fechamento do gânglio na cirurgia. Isto também ocorre porque algumas áreas nunca mais transpiram como o caso das mãos, ou áreas que transpiram menos. Ou seja, $40 \%$ das glândulas sudoríparas écrinas são desativadas. Como compensação, as outras $60 \%$ das glândulas que estão ativas tem que aumentar suas atividades. É uma consequência e efeitos negativos da cirurgia, são riscos que o paciente corre ao se submeter aos procedimentos.

De acordo com Dumont (2008) foram realizadas pesquisas com 80 pacientes operados pela hiperidrose por um semestre, com variação de idade até 56 anos, foi possível medir o nível de satisfação após o procedimento cirúrgico por meio de uma escala de avaliação. $\mathrm{E}$, de acordo com os resultados 68 pacientes, ou seja, a maioria teve a hiperidrose compensatória. (HC). Esta, foi classificada como leve, moderada ou severa. A maioria considerou satisfeita com os resultados e foi comprovado também por este e outros estudos que a $\mathrm{HC}$ foi mais intensa na região do dorso e abdômen. $\mathrm{O}$ principal desafio da medicina é desenvolver um procedimento que apresentasse uma solução total. Deste modo, todos são informados das probabilidades de adquirirem a $\mathrm{HC}$, bem como localizações e fatores que a determinam.

O fenômeno é uma resposta do hipotálamo. Para os pacientes que foram submetidos a cirurgia no segundo gânglio torácico (T2), a compensatória é muito mais 
intensa. E isto ocorre devido à localização e extensão dos gânglios e também por serem os gânglios que recebem respostas dos hipotálamos. Há muitos questionamentos entre os pesquisadores sobre como evitar que isto realmente ocorra. Mas, a maioria deles chegaram à conclusão de que também pode ser qual gânglio é bloqueado, uma vez que cada um deles é responsável por uma ou mais regiões do organismo, pode ser seccionado um gânglio responsável por uma região mais abrangente. Por exemplo, uma cirurgia que envolva ambos gânglios T2 e T4 provavelmente levaria a HC. Apesar de que há controvérsias se é as duas glândulas que simultaneamente apresentam o problema ou apenas a T2, sendo que já houve casos de médicos que optaram por seccionar apenas a T4 em casos de T2 para evitar a HC. (CHOU ET. AL. 2006).

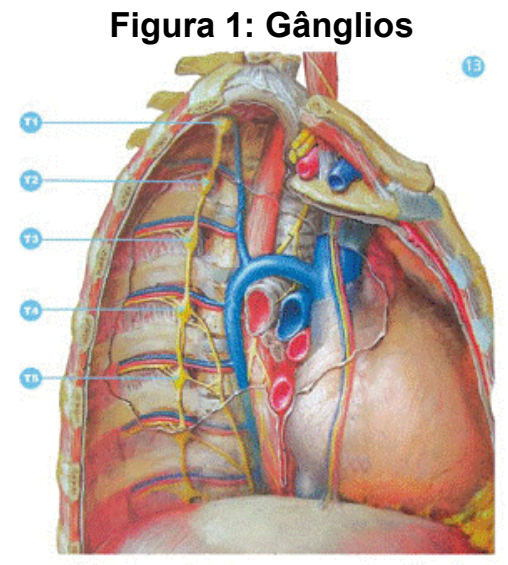

Fonte : Atlas

A HC também pode não apresentar os sintomas de imediato, desenvolvendose após, ou como também, pode diminuir com o passar do tempo. E esta apresenta grande relação com o clima, sendo mais acentuada em climas quentes e úmidos. Um fator limitante dos estudos realizados até agora é que um mesmo paciente pode quantificar de maneira diferente a intensidade da sudorese em poucos dias.

Nota-se a dificuldade de roupas que ajuda nesta questão ergonômica em regiões específicas nas quais se manifestaram a sudorese compensatória, e para isso também se é necessário um vestuário que não deixe de perder a estética por resolver questões práticas e funcionais.

Figura 2: Compensatória

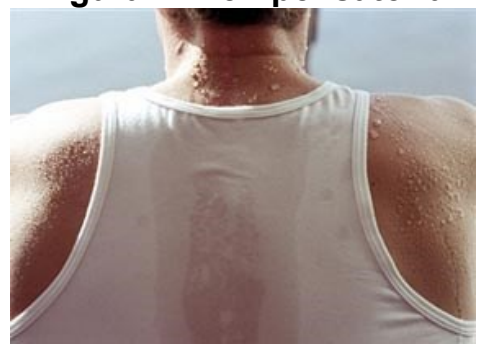

Fonte: Disponível em: <http://hiperidrose.drmalucelli.com.br/tudo-sobre-a-cirurgia/efeitoscolaterais-e-complicacoes/tratamentos-para-o-suor-compensatorio/> Acesso em jun 2016 


\section{MATERIAIS E MÉTODOS}

Foi elaborado um questionário online, utilizando a plataforma online "Google Form" onde cerca de 112 pessoas responderam, foram eliminadas do estudo todas que apresentavam uma faixa etária próxima a menopausa, entre 45 a 60 anos, que de acordo com estudos esta idade se encontra entre o climatério, bem como as ondas de calor e sudorese noturnas. (NEVES E PASCHOARELLI, 2015). Deste modo, foram feitas perguntas tanto para pessoas que apresentavam a disfunção quanto as que não apresentavam, foi aberto para ambos os gêneros a partir dos 18 anos até a idade descrita nos estudos como referente ao climatério da mulher.

Figura 3: Questionário Online $1^{\text {a }}$ Parte
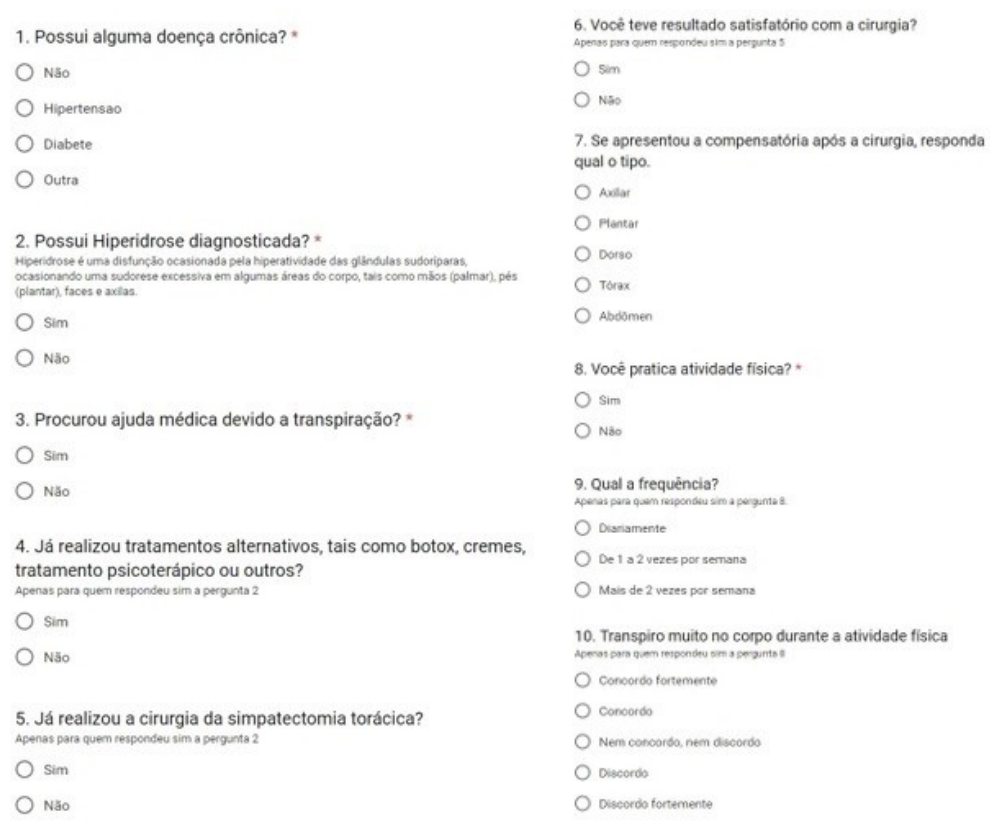

Fonte:

https://docs.google.com/forms/d/1Mmvgt28fWchk31rPfUcHxuEX_TVdCEmZRd9FLDde_4l/edit

Figura 4: Questionário Online $2^{\text {a }}$ Parte 

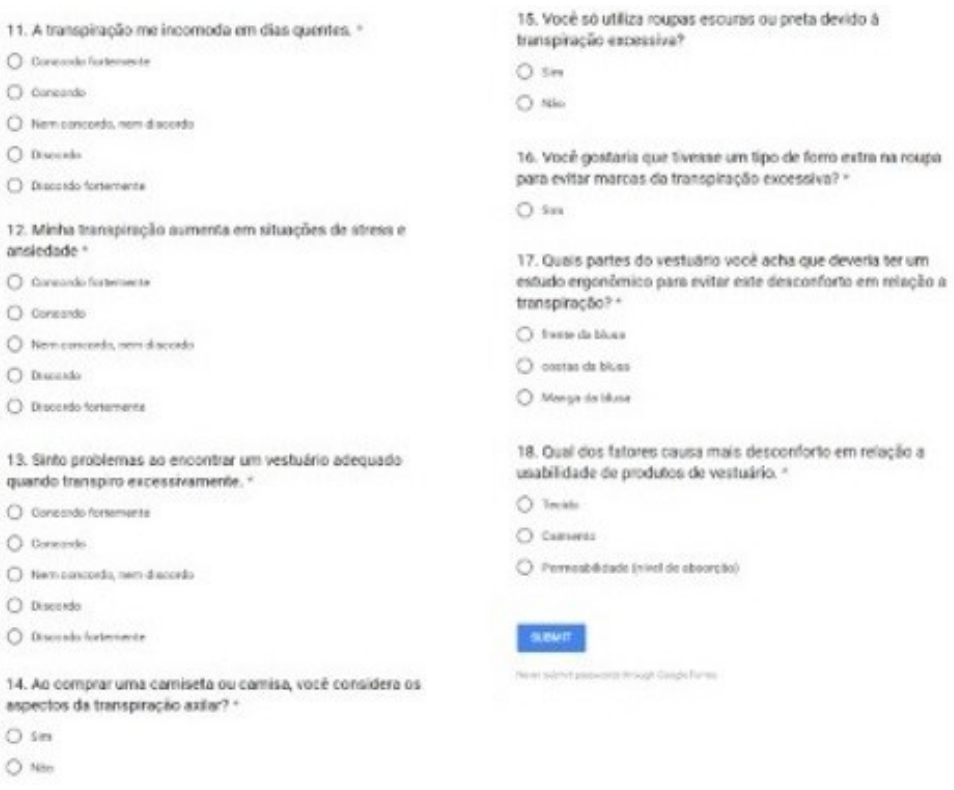

Fonte:

https://docs.google.com/forms/d/1Mmvgt28fWchk31rPfUcHxuEX_TVdCEmZRd9FLDde_4l/edit

\section{RESULTADOS E DISCUSSÕES}

Os resultados encontrados apresentaram os seguintes dados:

Figura 5: Diagnóstico de Hiperidrose plantar primária

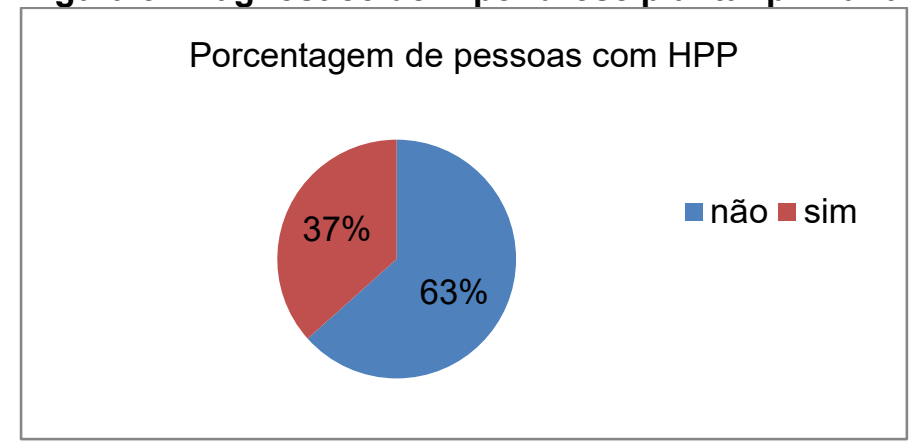

De acordo com o gráfico acima apenas uma minoria das pessoas entrevistadas possui a HP, resultando em 41 hiperidróticos.

$\mathrm{E}$, das 41 pessoas que disseram que tem hiperidrose diagnosticada, 23 destas pessoas já procuraram tratamentos alternativos tais como botox, cremes, tratamentos psicoterápicos ou outros. E, 11 destas pessoas que tem a hiperidrose já realizaram a cirurgia da simpatectomia torácica.

$\mathrm{E}$, quando questionadas se tiveram um resultado satisfatório com a cirurgia, cerca de $27 \%$ negaram estarem satisfeitas. $E$, das pessoas que realizaram a cirurgia, apenas uma delas não apresentou a HC (hiperidrose compensatória). Sendo que, das que apresentaram, o tórax e abdômen, foram as regiões mais afetadas pelo processo cirúrgico conforme (Figura 6). Seguidas do dorso e tórax em igual porcentagem. 
Figura 6: Efeito Compensatório após a cirurgia

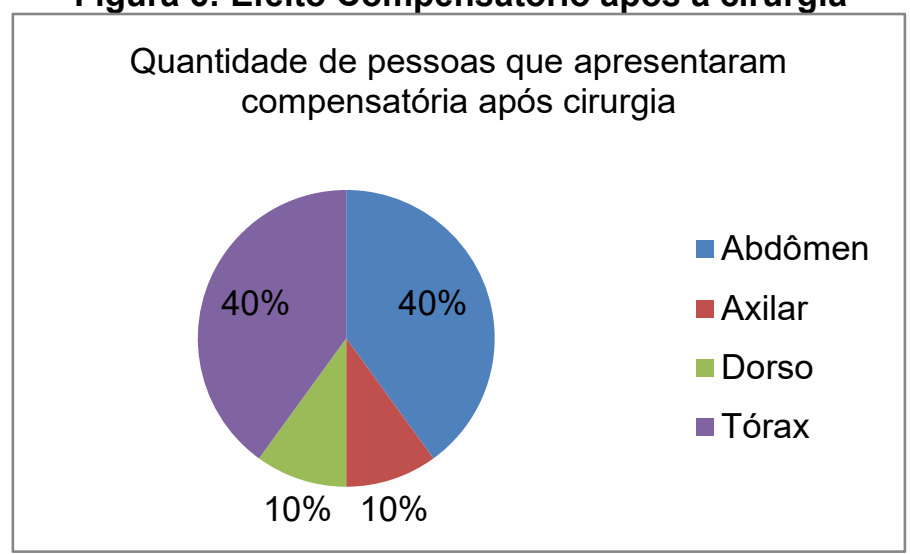

Apenas 87 pessoas responderam que praticam atividades físicas, sendo que, quando questionadas sobre a frequência a maioria respondeu que pratica de uma a duas vezes por semana. E a maioria delas, $63 \%$, somados $36 \%$ que concordam fortemente com $27 \%$ que concordam que transpiram muito no corpo durante a atividade física.

Em relação a pergunta se a transpiração incomoda em dias quentes, $72 \%$ responderam que concordam que a mesma incomoda, conforme figura $\mathrm{x}$ abaixo: $\mathrm{E}$, também um resultado expressivo apontou que a mesma incomoda em situações de stress e ansiedade, somando $69 \%$ das afirmações.

E, conforme (Figura 8), 55\% das pessoas afirmaram sentirem problemas ao encontrar um vestuário adequado quando transpiram excessivamente.

\section{Figura 7: Transpiração incomoda em dias quentes}

Quantidade de pessoas que relataram incômodo em dias quentes

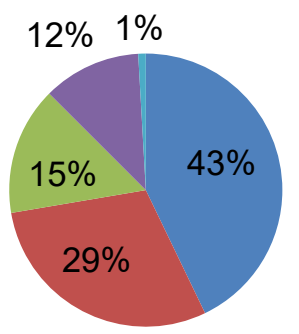

$$
\begin{aligned}
& \text { Concordo } \\
& \text { fortemente } \\
& \text { Concordo } \\
& \text { Nem concordo, } \\
& \text { nem discordo }
\end{aligned}
$$


Figura 8: Problemas para encontrar um vestuário adequado quando transpira excessivamente

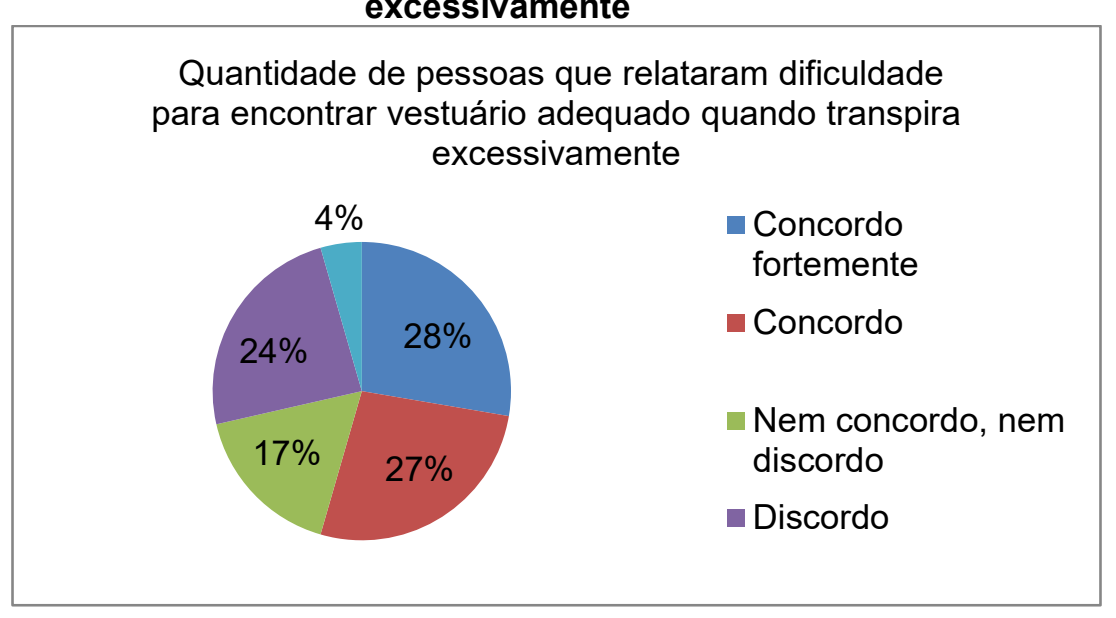

Também foi observado que um pouco mais que a metade das pessoas considera os aspectos da transpiração axilar ao comprar uma roupa, quando comparadas com o grupo que tem HP, a maioria do grupo considerou estes aspectos (Figura 9).

Figura 9: Consideração de aspectos da transpiração axilar ao comprar uma camiseta ou camisa

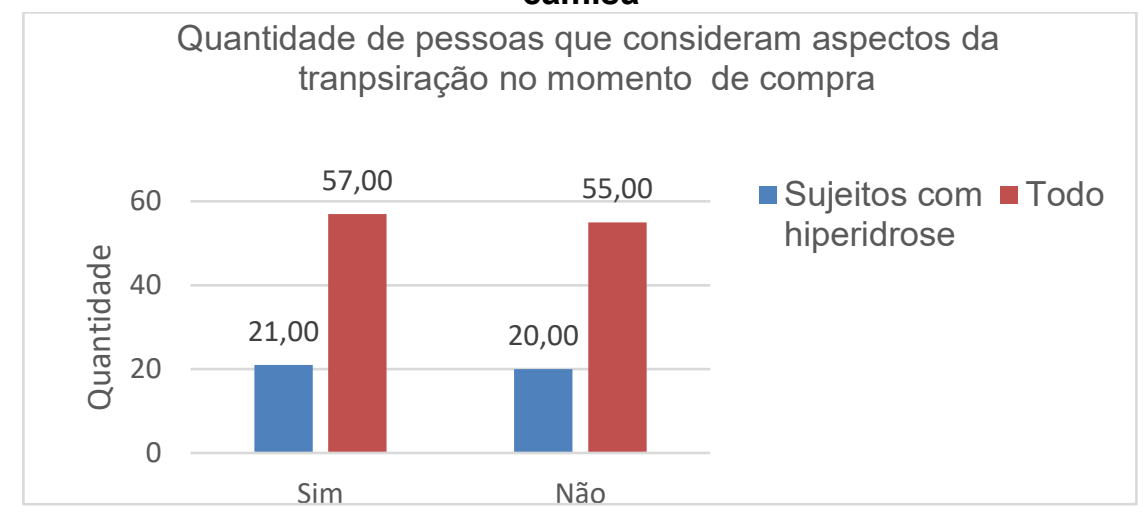

E quando questionadas se só usavam roupas escuras ou pretas devido à transpiração excessiva, apenas $21 \%$ responderam que sim em relação ao total. Sobre os sujeitos que tem hiperidrose metade respondeu que usariam roupas escuras. (Figura 10). Devido a isso, foi feito um questionamento se as pessoas gostariam que tivessem um tipo de forro extra na roupa para evitar marcas da transpiração excessiva, comparando o grupo das pessoas que tem hiperidrose, praticamente metade das pessoas afirmaram que gostariam e quando comparadas com o total teve a mesma proporção, conforme (Figura 11). 


\section{Figura 10: Uso de roupas escuras ou pretas devido à transpiração excessiva}

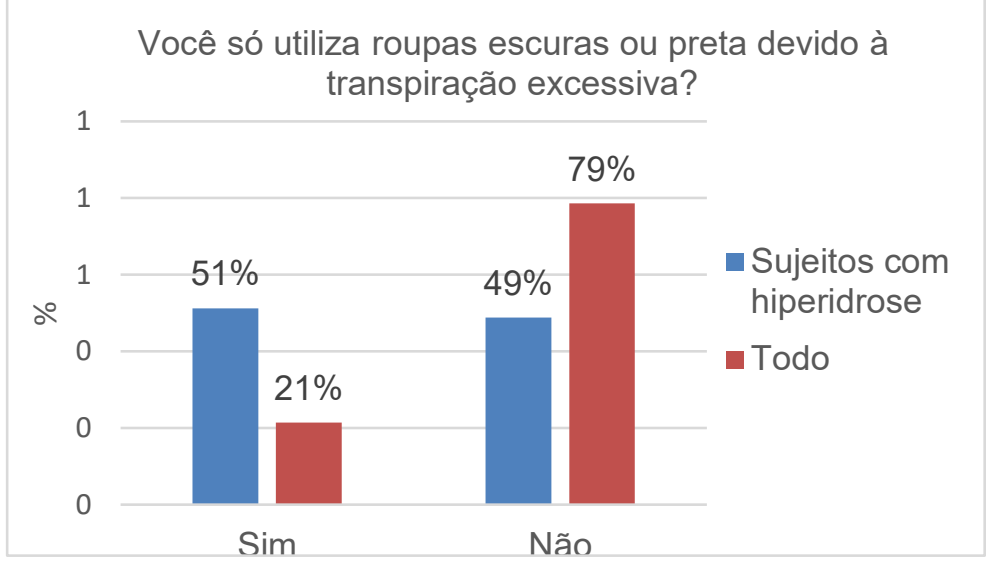

Figura 11: Se gostara de um tipo de forro extra na roupa para evitar marcas da transpiração excessiva

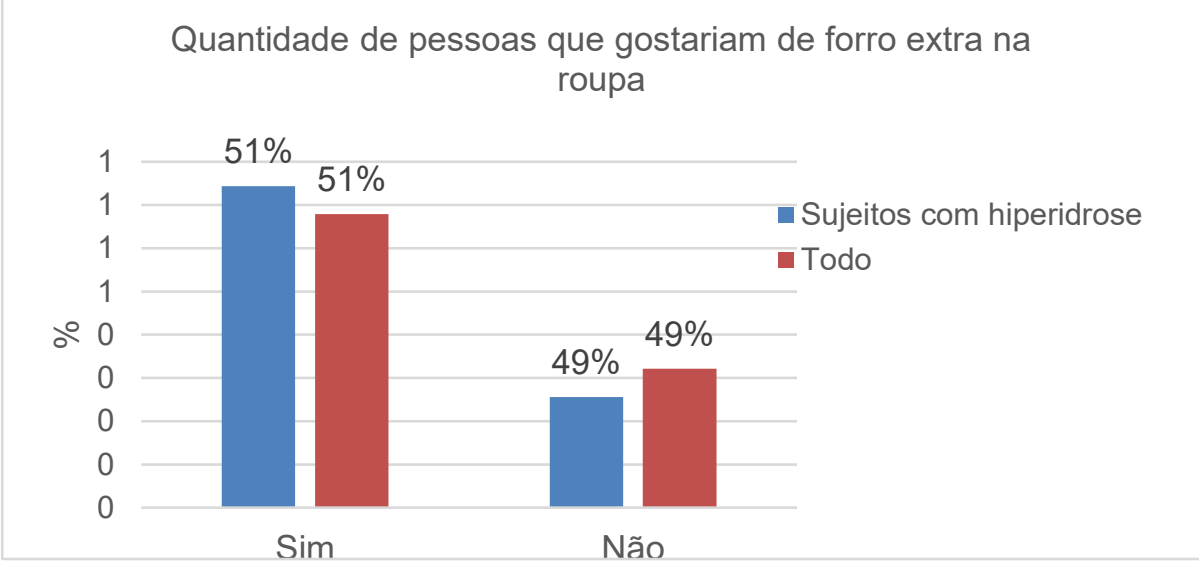

$\mathrm{E}$, finalmente, quando questionadas sobre qual parte do vestuário as mesmas gostariam que tivessem um estudo ergonômico para evitar os desconfortos em relação à transpiração, $59 \%$ gostaria que fosse estudada a manga da blusa, com $21 \%$ das pessoas que gostariam que fossem as costas da blusa, e, por último, $20 \%$ das respostas para a frente da blusa.

\section{CONCLUSÃO}

Foi possível observar com este estudo que do grupo de pessoas que apresentam a HP, por exemplo, em questões relacionadas ao desconforto no vestuário, foi notória a representatividade da maioria das respostas afirmando este quesito, um exemplo em relação ao desconforto térmico no momento da compra, também em relação a pergunta se as pessoas preferem roupas escuras devido à condição da transpiração excessiva. E, também em todas as demais questões relacionadas a um estudo ergonômico para este grupo de pessoas. Seja, em relação as partes do vestuário que precisariam serem melhoradas, que por ventura se relacionaram com as partes do corpo que sentem a hiperidrose compensatória. Por exemplo, a quantidade de pessoas que representaram terem compensatória no dorso, tórax e abdômen foram equivalentes a quantidade que afirmaram que gostariam de uma modelagem diferenciada no vestuário, tais como um forro extra ou até mesmo que preferem melhorias em relação às partes como manga, frente e costas da blusa. 
$\mathrm{E}$, entre o grupo de pessoas que não apresentam o problema, algumas questões apontaram desconforto na usabilidade do vestuário em dias quentes, e em situações de stress e ansiedade e alguma parte significativa em atividades físicas. São dados relevantes e que direciona para uma base científica que necessita de um estudo e melhorias em relação à interface deste público de pessoas com os produtos de moda.

\section{REFERÊNCIAS BIBLIOGRÁFICAS}

ALENCAR, O. C. de. Aplicabilidade do grupo focal para a avaliação do conforto em pesquisas de usabilidade em moda. Dissertação da USP, Escola de Artes, Ciências e Humanidades, São Paulo, 2014.

BROEGA, A. C.; SILVA, M. E. C. O conforto total do vestuário: design para os cinco sentidos. 2010.

CORSO, D. Coleção de calçados para mulheres com hiper-hidrose. Unversidadedo Vale do Itajaí. Balneário Camboriú, 2008.

COSTA, JR AS, LEAO L. E. V., SUCCI, JE, PEFEITO JA, FILHO AC, RYMKIEWICZ EF et. al. Randomized trial - oxybutynin for treatment of persistent plantar hyperhidrosis in women afer sympathectomy. Clinics. 2014; 69 (2): 101- 105.

CHOU, S. H.; KAO, E. L.; LIN, C. C.; et. al. The importance of classification in symapathetic surgery and a proposed mechanism for compensatory hyperhidrosis: experience with 464 cases. Surg. Endosc. 2006; 20:1749-53.

DUMONT, P. Side Effects and Complications of Surgery for Hyperhidrosis. Thorac Surg Clin. 2008; 18: 193-207.

HASIMOTO, E. N. Hiperidrose na cidade de Botucatu: prevalência, orientação, tratamento e qualidade de vida. Tese da UNESP. Botucatu, 2012.

MALAGI, M. E. Produto auxiliar para pessoas com hiperidrose. Trabalho de Conclusão de Curso. Cianorte, UEM, 2012.

MARTINS, S. B. O conforto no vestuário: uma interpretação da ergonomia. Tese para a obtenção do título de doutor no programa de Pós-Graduação em Engenharia de Produção da Universidade Federal de Santa Catarina. Florianópolis: UFSC, 2005.

MONTESSI, J. ALMEIDA, E. P. VIEIRA, J. P. ABREU, M. M. SOUZA, R. L. P. MONTESSI, O. V. D. Simpatectomia torácica por videotoracoscopia para tratamento da hiperidrose primária: estudo retrospectiva de 521 casos comparando diferentes níveis de ablação. J Bras Pneumol. 2007; 33 (3): 248- 254. Juiz de Fora, MG, 2007.

PORTAL PSD, Portal da Sociedade Brasileira de Dermatologia. Hiperidrose. Disponível em: <http:www.sbd.org.br/doenças/hiperidrose> Acesso em: 2015.

FIORELLI, R. K; ELLIOT, L. ALVARENGA, R. M. P.; MORARD, M. R. S.; ALMEIDA, C. R.; FIORELLI, S. K. A.; AGOGLIA, B. G. Avaliação do Impacto na Qualidade de Vida de Pacientes de Hiperidrose Primária Submetidos à Simpatectomia Videotoracoscópica. 
Revista Meta, v. 3, n. 7, 2011.

FRAGA, C. E. N. Monitoramento da Resistência Galvânica da Pele. PUC, Porto Alegre, 2009.

FROTA, A. B.; SCHIFFER, S. R. Manual de Conforto Térmico: Arquitetura e Urbanismo. $5^{a}$ Ed. São Paulo: Studio Nobel, 2001.

GONÇALVES, D. SANTOS, Y. M. Implementação de um Sistema de Business Inteligence para a análise da qualidade de vida pré e pós-operatória.Guimarães: Universidade do Minho, 2010.

IIDA, I. Ergonomia, projeto e produção. São Paulo: Ed. Edgard Blucher, 2005.

NEVES, E. P. das.; PASCHOARELLI, L. C. Moda e Design Ergonômico: Influência de variáveis biopsicosensoriais do climatério e da menopausa na percepção de usabilidade do vestuário feminine. Dissertação da Faculdade de Artes, Arquitetura e Design da UNESP. Bauru, 2015.

TU, Y. R.; LI, X.; LIN, M. et. al. Epidemiological survey of primary palmar hyperhidrosis in adolescent in Fuzhou of people's Republic of China. Eur J Cardiothorac Surg. 2007; 31:737-9.

YASBEK, G. Comparação dos resultados obtidos no tratamento da hiperidrose palmar pela simpatectomia torácica videotoracoscópica nos níveis de desnervação: T2 e T3. Tese da Faculdade de Medicina da Universidade de São Paulo. USP, São Paulo, 2009. 